\title{
Na-doped $\mathrm{LiMnPO}_{4}$ as an electrode material for enhanced lithium ion batteries
}

\author{
K RAJAMMAL $^{1}$, D SIVAKUMAR ${ }^{2}$, NAVANEETHAN DURAISAMY ${ }^{1, *}$, K RAMESH $^{1}$ \\ and S RAMESH ${ }^{1}$ \\ ${ }^{1}$ Center for Ionics University of Malaya, Department of Physics, University of Malaya, Kuala Lumpur 50603, Malaysia \\ ${ }^{2}$ Faculty of Mechanical Engineering, University Technical Malaysia Melaka (UTeM), 76100 Durian Tunggal, Malaysia
}

MS received 20 October 2015; accepted 27 June 2016

\begin{abstract}
We report the influence of sodium (Na)-incorporated lithium manganese phosphate as an active material on its performance in electrochemical study for energy storage application. $\mathrm{Li}_{1-x} \mathrm{Na}_{x} \mathrm{MnPO}_{4}$ with different mole ratios $(0.00 \leq x \leq \mathbf{0 . 0 5})$ of sodium is synthesized via a simple sol-gel method. The discharge capacity of $\mathrm{Li}_{1-x} \mathrm{Na}_{x} \mathrm{MnPO}_{4}$ varies with respect to mole ratios of sodium incorporated. The maximum discharge capacity of $92.45 \mathrm{mAh} \mathrm{g}{ }^{-1}$ is observed in $\mathrm{Li}_{0.97} \mathrm{Na}_{0.03} \mathrm{MnPO}_{4}$, which is higher than that of pristine $\mathrm{LiMnPO}_{4}$ and other Na-incorporated $\mathrm{LiMnPO}_{4}$. The maximum cyclic stability is found to be $84.15 \%$ up to 60 cycles. These results demonstrate that $\mathrm{Li}_{0.97} \mathrm{Na}_{0.03} \mathrm{MnPO}_{4}$ plays a significant role in future energy storage application.
\end{abstract}

Keywords. $\mathrm{LiMnPO}_{4}$; sodium doping; cathode materials; electrochemical study; lithium ion batteries.

\section{Introduction}

Hybrid electric vehicles require lithium rechargeable batteries because of their excellent power density and long life time [1]. Cathode is the most important element within the lithium batteries, which gives significant impact on capacity and electrochemical performance. Lithium manganese phosphate $\left(\mathrm{LiMnPO}_{4}\right)$ is mainly focused as a suitable candidates in the olivine group among $\mathrm{LiFePO}_{4}, \mathrm{LiCoPO}_{4}$ and $\mathrm{LiNiPO}_{4}$ for cathode application [2,3]. In $\mathrm{LiMnPO}_{4}$, the $\mathrm{P}-\mathrm{O}$ covalent bond enables good thermal and cycling stability $[4,5]$. The theoretical energy density of $\mathrm{LiMnPO}_{4}$ is $701 \mathrm{Wh} \mathrm{kg}^{-1}$ with poor lithium diffusion and low electronic/ionic conductivity, which affect the electrochemical property [6,7].

Various synthesis methods are developed to overcome these drawbacks, which focus mainly on particle size control [8-10], carbon coating [11,12] and cation doping [13-15]. Moreover, the surface morphologies are an essential factor for electrochemical properties. Recently haemoglobin-like $\mathrm{LiMnPO}_{4}$ microspheres were prepared for better electrochemical activity due to presence of three-dimensional (3D) hierarchical structures [16]. $\mathrm{LiMnPO}_{4}$ nanorods $(<30 \mathrm{~nm})$ are produced by controlling boiling temperature, solvent, concentration of surfactants, reaction temperature and time [17]. Cui et al [18] reported that irregular flaky shaped $\mathrm{LiMnPO}_{4}$ is achieved by a hollow-sphere $\mathrm{Li}_{3} \mathrm{PO}_{4}$ precursor, which is used to control the particle growth of $\mathrm{LiMnPO}_{4}$. Also, Doi et al [9] stated that by controlling particle size,

*Author for correspondence (naveennanoenergy@ gmail.com) the diffusion and conduction path are shortened, which lead to improvement of conductivity. On the other hand, Nam et al [19] reported that the carbon-coated nanostructured $\mathrm{LiMnPO}_{4}$ via combination of spray pyrolysis and dry ball milling revealed good electrochemical properties at high temperature and high charge/discharge rate of $2 \mathrm{C}$. Herein, carbon layer is also found to be effectively suppress the crystal growth during heat treatment, resulting in a significant improvement of cycling performance [11].

Cation doping in $\mathrm{LiMnPO}_{4}$ is found to be an alternative method to upgrade ionic conductivity [13]. Recent work indicated that cesium (Ce)-doped $\mathrm{LiMnPO}_{4}$ led to easy diffusion of lithium ion in bulk materials [20]. In another work, electrochemically inactive cations were replaced partially for $\mathrm{Mn}$; thus $\mathrm{LiMn}_{0.88} \mathrm{Mg}_{0.1} \mathrm{Zr}_{0.02} \mathrm{PO}_{4}$ exhibited high discharge capacity (134.0 mAh g ${ }^{-1}$ ) and lower irreversible capacity loss [21]. This enhancement is accredited to good kinetic properties due to the reduced distortion of local structure. Co-substituted iron $(\mathrm{Fe})$ and magnesium $(\mathrm{Mg})$ evenly spread over $\mathrm{LiMnPO}_{4}$, leading to shrinkage of crystal lattice [22]. Considering this fact, this work is an effort to improve $\mathrm{LiMnPO}_{4}$ by partial natrium substitution on lithium sites. The ionic radius of natrium $(0.098 \mathrm{~nm})$ is bigger than that of lithium $(0.076 \mathrm{~nm})$; thus it is highly possible to increase the interlayer space for facile lithium movement during intercalation and deintercalation processes [23,24]. $\mathrm{Na}$ element is inexpensive, ample and environment friendly [23]. Several attempts have been done to improve electrochemical performance of cathode materials by partial natrium doping. $\mathrm{Li}_{1.17} \mathrm{Na}_{0.03}\left[\mathrm{Co}_{0.13} \mathrm{Ni}_{0.13} \mathrm{Mn}_{0.54}\right] \mathrm{O}_{2}$ demonstrated high discharge capacity, larger coulombic efficiency, enhanced rate capability and cycling stability as compared 
with $\mathrm{Li}_{1.17} \mathrm{Na}_{0.03}\left[\mathrm{Co}_{0.13} \mathrm{Ni}_{0.13} \mathrm{Mn}_{0.54}\right] \mathrm{O}_{2}$ [24]. Chen et al [25] reported that $\mathrm{Na}^{+}$substitution for $\mathrm{Li}^{+}$minimizes cation mixing, improves reversibility and restricts charge transfer impedance during cycling.

The present work reports the preparation and electrochemical characterizations of $\mathrm{Li}_{1-x} \mathrm{Na}_{x} \mathrm{MnPO}_{4}$ with different mole ratios of sodium, $x=0.00,0.01,0.02,0.03,0.04$ and 0.05 . To the best of our knowledge, partial $\mathrm{Na}^{+}$substitution for $\mathrm{Li}^{+}$site has not been focused for $\mathrm{LiMnPO}_{4}$-based energy storage application.

\section{Experimental}

\subsection{Materials}

Lithium acetate $\left(\mathrm{LiC}_{2} \mathrm{H}_{3} \mathrm{O}_{2}\right)$ and sodium acetate $\left(\mathrm{C}_{2} \mathrm{H}_{3} \mathrm{NaO}_{2}\right)$ were purchased from Aldrich. Manganese acetate $\mathrm{Mn}\left(\mathrm{CH}_{3}\right.$ $\mathrm{COO})_{2} \cdot 4 \mathrm{H}_{2} \mathrm{O}$ and ammonium dihydrogen phosphate $\left(\mathrm{NH}_{4}\right)$ $\mathrm{H}_{2} \mathrm{PO}_{4}$ were obtained from Friendmann Schmidt.

\subsection{Synthesis process}

$\mathrm{Li}_{1-x} \mathrm{Na}_{x} \mathrm{MnPO}_{4}(0.00 \leq x \leq 0.05)$ was synthesized by the sol-gel method. Lithium acetate, sodium acetate and manganese acetate were dissolved together with ammonium dihydrogen phosphate in the molar ratios $1: x=0.00$, $0.01,0.02,0.03,0.04,0.05: 1: 1$. Dissolution of this mixture was done in distilled water under magnetic stirring at $120^{\circ} \mathrm{C}$ and maintained until a solid product was formed. Finally, the obtained solid material was sintered at $700^{\circ} \mathrm{C}$ for $3 \mathrm{~h}$.

\subsection{Structural and electrochemical characterizations}

XRD measurements were obtained using a Siemens D 5000 diffractometer with $\mathrm{Cu}-\mathrm{K} \alpha$ radiation $(\lambda=1.54060 \AA)$. The diffraction intensity was recorded in the range $10-80^{\circ}$ with step size $0.02^{\circ}$. The surface morphology of synthesized samples was examined by field emission scanning electron microscopy (microscope model JSM 7600-F).

To prepare thin films, $80 \mathrm{wt} \%$ of active materials $\left(\mathrm{Li}_{1-x} \mathrm{Na}_{x} \mathrm{MnPO}_{4}\right)$ was mixed with $20 \mathrm{wt} \%$ of carbon, 20 $\mathrm{mg}$ of $\mathrm{Li}_{1-x} \mathrm{Na}_{x} \mathrm{MnPO}_{4} / \mathrm{C}$ and $8 \mathrm{mg}$ of teflonized acetylene (TAB) in ethanol medium, followed by pressing on a stainless steel mesh and then dried at $120^{\circ} \mathrm{C}$ for $12 \mathrm{~h}$. Then, the cell was assembled in an argon atmosphere using $\mathrm{Li}_{1-x} \mathrm{Na}_{x} \mathrm{MnPO}_{4}$-based electrode as a cathode, lithium metal as an anode and $1 \mathrm{M} \mathrm{LiPF}_{6}$ dissolved in a mixture of ethylene carbonate (EC)/dimethyl carbonate (DMC) $(1: 1$ in volume) as an electrolyte. Cyclic voltammetry tests were carried out using an auto lab in the potential range of $2.5-4.5 \mathrm{~V}$. All the samples were charged at $1.0 \mathrm{~mA}$ and discharged at $0.5 \mathrm{~mA}$ between 2.5 and $4.5 \mathrm{~V}$ on a Neware battery system $(\mathrm{AC} 10 \mathrm{mV})$. Electrochemical impedance spectroscopy (EIS) tests were carried out using a Gamry instrument in the frequency range of $0.05 \mathrm{~Hz}-10 \mathrm{kHz}$.

\section{Results and discussion}

The structural crystallinity was examined using the XRD pattern. Figure 1 presents the patterns of pristine $\mathrm{LiMnPO}_{4}$ and $\mathrm{Li}_{1-x} \mathrm{Na}_{x} \mathrm{MnPO}_{4}(0.00 \leq x \leq 0.05)$. The observed diffraction peaks at $2 \theta=20.4,25.1,29.1$ and $35.07^{\circ}$ correspond to $(011),(111 / 021),(200 / 121)$ and (131) planes, respectively. This was well indexed to the orthorhombic structure of $\mathrm{LiMnPO}_{4}$ (JCPDS No. 33-804) with space group of Pnmb $[15,16]$. However, the lattice parameters varied due to $\mathrm{Na}$ metal doping in $\mathrm{LiMnPO}_{4}$, which are given in table 1.

Both $a$ and $c$ lattices expand with increasing Na metal doping. $c$-Axis enlargement indicates the expansion of Li pathway within the structure [26]. Also, the enlargement in $a$ site provides smoother Li diffusion during the intercalation process. Moreover it has been proved by the simulation method that $\mathrm{Li}$ ion moves through the $a$-axis due its lower activation energy, which was supported by Oh et al [27]. Therefore, this provides smoother Li diffusion during the intercalation process, suggesting enhanced electrochemical performance [24].

FESEM analysis was used to study the surface morphology of synthesized samples. Figure 2 displays surface morphology of $\mathrm{Li}_{1-x} \mathrm{Na}_{x} \mathrm{MnPO}_{4}(0.00 \leq x \leq 0.05)$ particles formed at $700^{\circ} \mathrm{C}$ (calcination temperature). Agglomeration

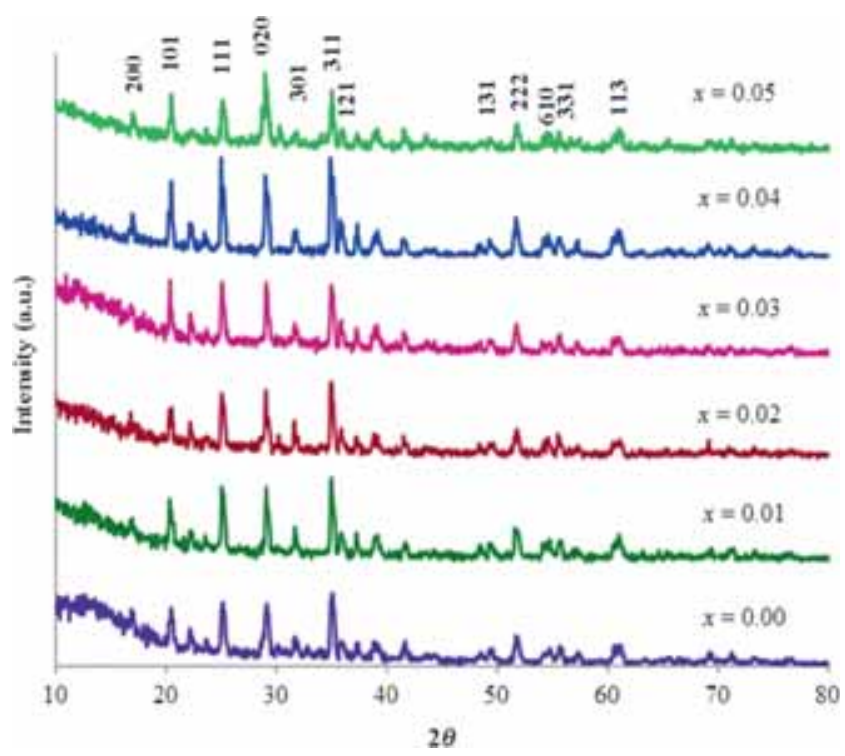

Figure 1. $\mathrm{XRD}$ of $\mathrm{Li}_{1-x} \mathrm{Na}_{x} \mathrm{MnPO}_{4}(0.00 \leq x \leq 0.05)$ sintered at $700^{\circ} \mathrm{C}$.

Table 1. Calculated lattice parameters of $\mathrm{Li}_{1-x} \mathrm{Na}_{x} \mathrm{MnPO}_{4}$ $(0.00 \leq x \leq 0.05)$.

\begin{tabular}{lll}
\hline$x$ in $\mathrm{Li}_{1-x} \mathrm{Na}_{x} \mathrm{MnPO}_{4}$ & $a(\AA)$ & $c(\AA)$ \\
\hline 0.00 & 6.117 & 4.718 \\
0.01 & 6.122 & 4.734 \\
0.02 & 6.126 & 4.740 \\
0.03 & 6.131 & 4.750 \\
0.04 & 6.136 & 4.765 \\
0.05 & 6.137 & 4.784 \\
\hline
\end{tabular}



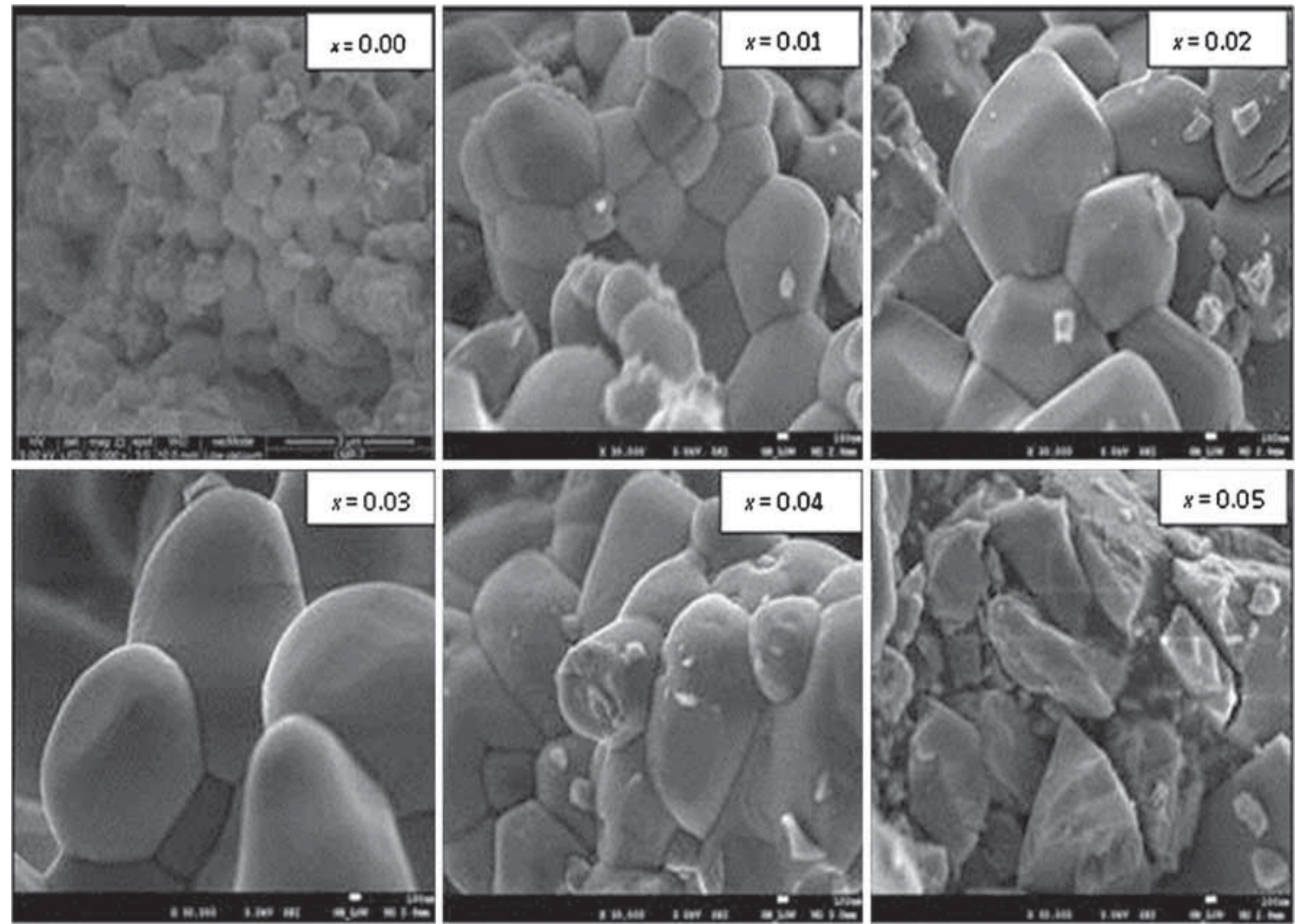

Figure 2. FESEM images of $\mathrm{Li}_{1-x} \mathrm{Na}_{x} \mathrm{MnPO}_{4}(x=0.00,0.01,0.02,0.03,0.04$ and 0.05$)$ particles.

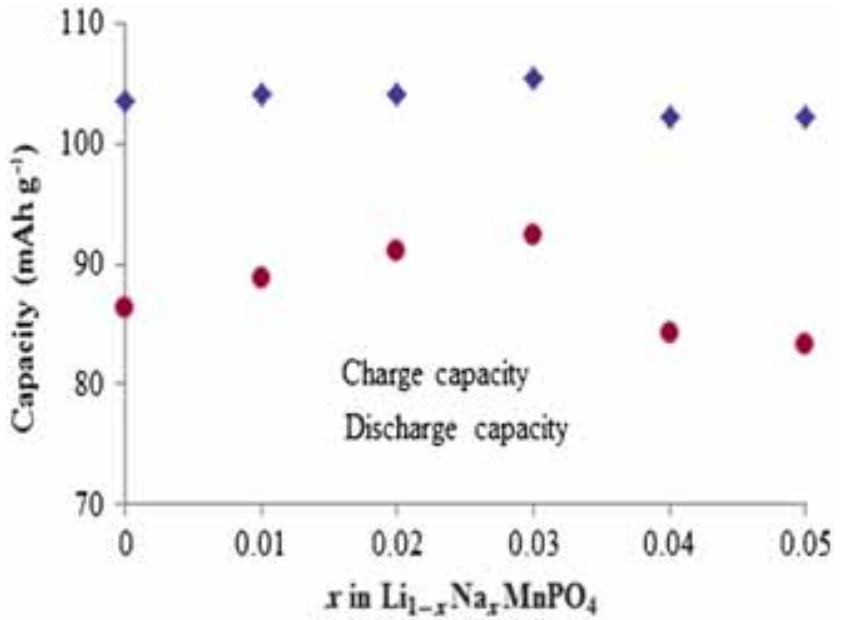

Figure 3. Initial charge and discharge capacities of $\mathrm{Li}_{1-x} \mathrm{Na}_{x}$ $\mathrm{MnPO}_{4}$ particles.

that occurs from $x=0.00$ until $x=0.03$ was higher as compared with $x=0.04$ and $x=0.05$. Agglomerated particles and individual particles are present together in the samples and agglomerated particles are formed by smaller individual particles.

Figure 3 clearly displays that the initial charge and discharge capacities increase from $x=0.00$ to $x=0.03$ and then tend to decrease until $x=0.05$. Irreversible capacity loss decreases with addition of $\mathrm{Na}^{+}$in the $\mathrm{Li}^{+}$site. Less

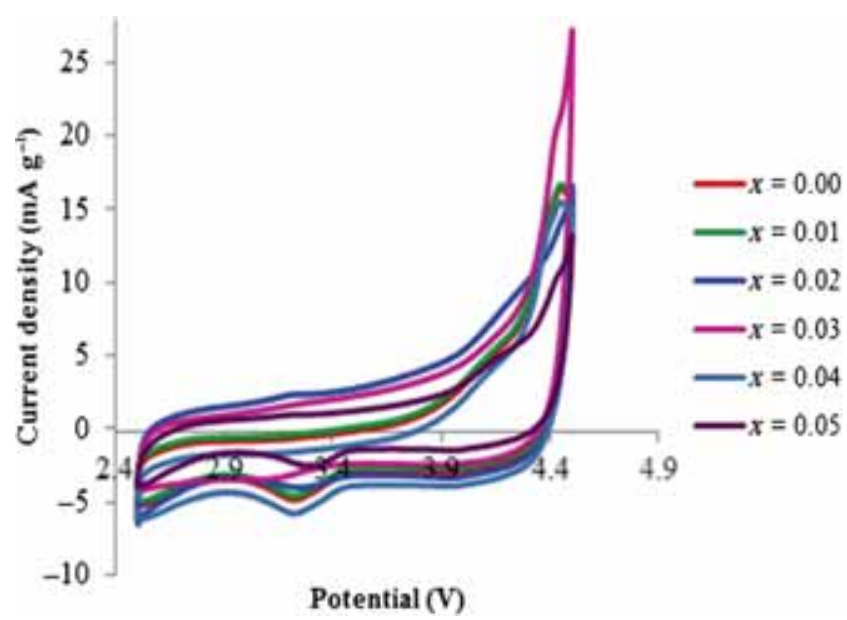

Figure 4. Cyclic voltammetry of $\mathrm{Li}_{1-x} \mathrm{Na}_{x} \mathrm{MnPO}_{4}(0.00 \leq x \leq$ 0.05 ) samples at scan rate of $0.2 \mathrm{mV} \mathrm{s}^{-1}$.

irreversible loss observed in $\mathrm{Li}_{0.97} \mathrm{Na}_{0.03} \mathrm{MnPO}_{4}$ was found to be $\left(4.1 \mathrm{mAh} \mathrm{g}^{-1}\right)$ lesser than that of pristine $\mathrm{LiMnPO}_{4}$ $\left(11.5 \mathrm{mAh} \mathrm{g}^{-1}\right)$. Also, the maximum capacity values were recorded at $x=0.03$. A similar pattern was observed for continuous electrochemical cycling. Therefore, the enhanced cycling performance is attributed to the structure stabilization with $\mathrm{Na}^{+}$ions, which act as a pillar [20,21].

Cyclic voltammograms for $\mathrm{Li}_{1-x} \mathrm{Na}_{x} \mathrm{MnPO}_{4}(x=0.00$, $0.01,0.02,0.03,0.04$ and 0.05$)$ are shown in figure 4. 


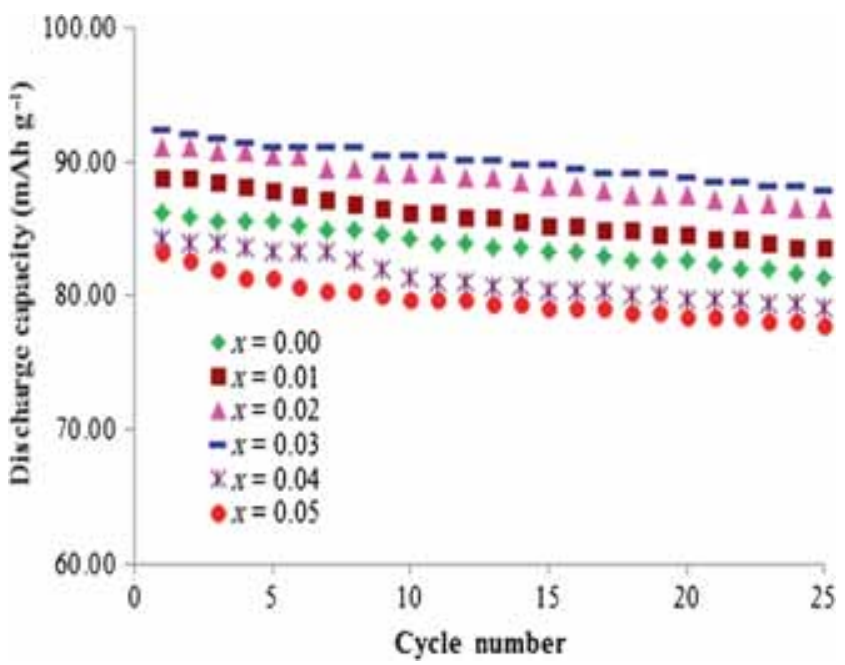

Figure 5. Discharge capacities of $\mathrm{Li}_{1-x} \mathrm{Na}_{x} \mathrm{MnPO}_{4}(0.00 \leq x \leq$ 0.05 ) particles at current $0.5 \mathrm{~mA}$.

Cyclic voltammetry depicts similar patterns as the Na substitution varies at a minor level. Interestingly, anodic and cathodic peaks become sharper as Na substitution level rises to $x=$ 0.03 in $\mathrm{Li}_{1-x} \mathrm{Na}_{x} \mathrm{MnPO}_{4}$. This clearly denotes partial substitution of $\mathrm{Li}$ by $\mathrm{Na}$, which increases peak currents, resulting in the improvement of electrochemical properties [28].

Figure 5 illustrates the discharge capacities of $\mathrm{Li}_{1-x} \mathrm{Na}_{x}$ $\mathrm{MnPO}_{4}(0.00 \leq x \leq 0.05)$ in the voltage range of $2.5-4.5 \mathrm{~V}$ at current rate $0.2 \mathrm{C}$. It presents initial discharge capacities of 86.3, 88.9, 91.2, 92.4, 84.3 and 83.3 $\mathrm{mAh} \mathrm{g}^{-1}$ for $x=0.00$, $0.01,0.02,0.03,0.04$ and 0.05 in $\mathrm{Li}_{1-x} \mathrm{Na}_{x} \mathrm{MnPO}_{4}$, respectively. At the same time, coulombic efficiency improved from $83.3 \%$ (pristine $\mathrm{LiMnPO}_{4}$ ) to $87.6 \%\left(\mathrm{Li}_{0.97} \mathrm{Na}_{0.03} \mathrm{MnPO}_{4}\right)$. $\mathrm{Na}^{+}$ions act as pillars, providing wider space for lithium ions movement $[20,21]$. This improved the intercalation and deintercalation processes within the materials and smoothened them [29]. Apart from these, Jahn Teller distortion is related to the $\mathrm{Mn}-\mathrm{Mn}$ distance in the crystalline structure. Here, $\mathrm{Na}$ substitution made $\mathrm{Mn}-\mathrm{Mn}$ distance longer as $\mathrm{Na}^{+}$ions are larger compared with $\mathrm{Li}^{+}$ions. This weakens the Jahn Teller effect and also yields strong cycling stability [30].

The mole ratio of 0.03 in $\mathrm{Li}_{1-x} \mathrm{Na}_{x} \mathrm{MnPO}_{4}$ was found to be the maximum level of doping that enhances cycling properties [31]. Beyond this the addition of $\mathrm{Na}(>0.03)$ deteriorates the capacitive nature due to structural instability and weak electrochemical performance [30,32]. $\mathrm{Li}_{0.97} \mathrm{Na}_{0.03} \mathrm{MnPO}_{4}$ demonstrated the maximum cycling stability compared with other samples with moderate doping of $\mathrm{Na}$.

Figure 6 displays the capacity retention of $\mathrm{Li}_{0.97} \mathrm{Na}_{0.03}$ $\mathrm{MnPO}_{4}$ for 60 cycles. Initial charge capacity of $\mathrm{Li}_{0.97} \mathrm{Na}_{0.03}$ $\mathrm{MnPO}_{4}$ was found to be $105.4 \mathrm{mAh} \mathrm{g}^{-1}$, which results in irreversible capacity of $12.9 \mathrm{mAh} \mathrm{g}^{-1}$. Capacity retention based on initial discharge capacity reaches about $97.89 \%$ at the $10^{\text {th }}$ cycle, $96.12 \%$ at the $20^{\text {th }}$ cycle, $92.96 \%$ at the $30^{\text {th }}$ cycle, $90.49 \%$ at the $40^{\text {th }}$ cycle and $87.32 \%$ at the $50^{\text {th }}$ cycle. It delivers discharge capacity of $77.80 \mathrm{mAh} \mathrm{g}^{-1}$ at the $60^{\text {th }}$ cycle, which is able to retain $84.15 \%$ of its initial discharge capacity of $92.4 \mathrm{mAh} \mathrm{g}^{-1}$.

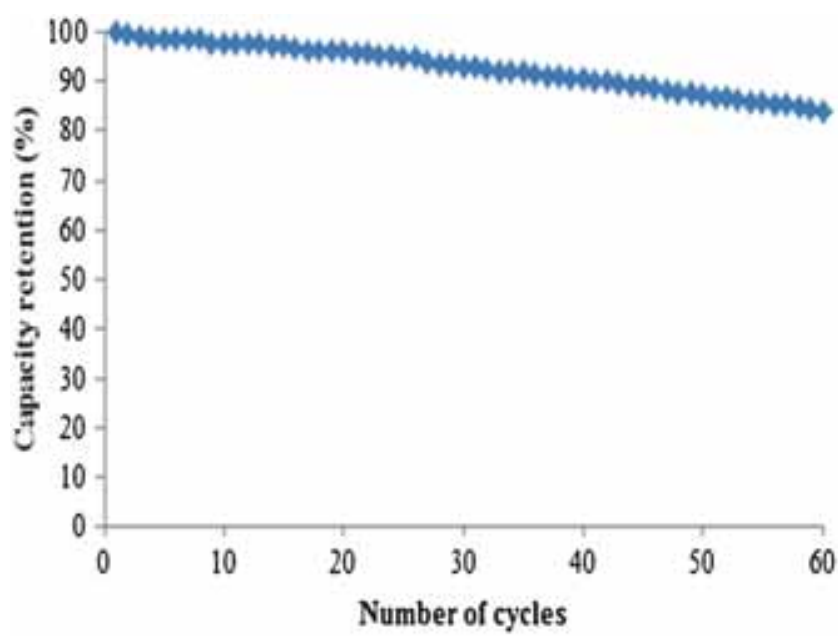

Figure 6. Capacity retention of $\mathrm{Li}_{0.97} \mathrm{Na}_{0.03} \mathrm{MnPO}_{4}$ at current $0.5 \mathrm{~mA}$

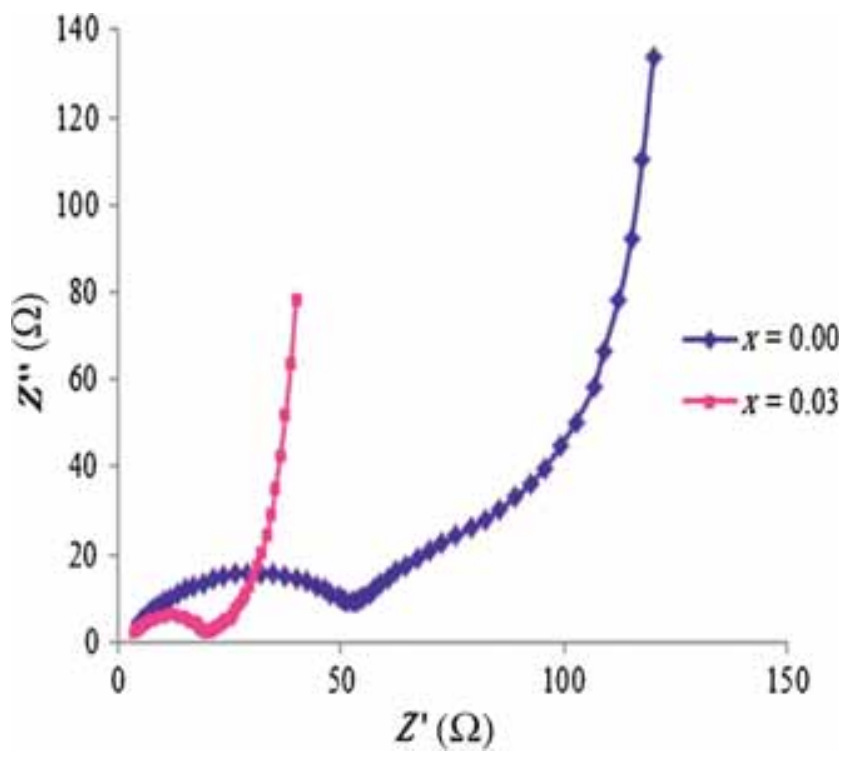

Figure 7. Impedance spectra of $\mathrm{LiMnPO}_{4}$ and $\mathrm{Li}_{0.97} \mathrm{Na}_{0.03} \mathrm{MnPO}_{4}$ from EIS measurements.

Impedance spectra of $\mathrm{LiMnPO}_{4}$ and $\mathrm{Li}_{0.97} \mathrm{Na}_{0.03} \mathrm{MnPO}_{4}$ can be observed in figure 7. It is noteworthy that semicircles of Na-substituted $\mathrm{LiMnPO}_{4}$ samples exhibit smaller radius compared with $\mathrm{LiMnPO}_{4}$. This ascertains increased electronic conductivity and hence facilitates smooth lithium ion movement into active materials [32]. The observed $R_{\mathrm{ct}}$ value for $\mathrm{LiMnPO}_{4}$ is around $57 \Omega$, while $R_{\mathrm{ct}}$ of $\mathrm{Li}_{0.97} \mathrm{Na}_{0.03} \mathrm{MnPO}_{4}$ is found to be about $19 \Omega$. This describes that partial $\mathrm{Na}$ substitution is able to reduce charge transfer resistance [25].

\section{Conclusion}

This work demonstrated the effect of $\mathrm{Na}$ doping in $\mathrm{LiMnPO}_{4}$. $\mathrm{Na}$ of different concentrations was substituted in the 
$\mathrm{LiMnPO}_{4}$ system via the sol-gel method. The XRD pattern confirmed the well-indexed crystalline structure. Addition of $\mathrm{Na}$ ions into the crystal structure expands the Li slab space. The maximum discharge capacity of $92.45 \mathrm{mAh} \mathrm{g}^{-1}$ was achieved in $\mathrm{Li}_{0.97} \mathrm{Na}_{0.03} \mathrm{MnPO}_{4}$, compared with pristine $\mathrm{LiMnPO}_{4}\left(86.26 \mathrm{mAh} \mathrm{g}^{-1}\right)$, with the maximum cyclic stability of $84.15 \%$ up to 60 cycles. Irreversible capacity loss was reduced by natrium addition $\left(\mathrm{Li}_{0.97} \mathrm{Na}_{0.03} \mathrm{MnPO}_{4}\right.$ compared with pristine $\mathrm{LiMnPO}_{4}$ ). Therefore, these experimental results suggested that superior electrochemical performance can be attained through optimizing adequate $\mathrm{Na}$ doping in $\mathrm{LiMnPO}_{4}$ towards lithium ion battery application.

\section{Acknowledgements}

We would like to thank financial support from the University of Malaya via PPP grant PG 099 - 2014B and Fundamental Research Grant Scheme (FP012-2015A) from the Ministry of Education, Malaysia.

\section{References}

[1] Kim J, Seo D, Kim S, Park Y and Kang K 2010 Chem. Commun. 461305

[2] Koleva V, Zhecheva E and Stoyanova R 2011 Dalton Trans. 407385

[3] Zhang W, Shan Z, Zhu K, Liu S, Liu X and Tian J 2015 Electrochim. Acta 153385

[4] Yoshida J, Stark M, Holzbock J et al 2013 J. Power Sources 226122

[5] Qin Z, Zhou X, Xia Y, Tang C and Liu Z 2012 J. Mater. Chem. 2221144

[6] Aono S, Urita K, Yamada H and Moriguchi I 2012 Solid State Ion 225556

[7] Dong Y, Wang L, Zhang S et al 2012 J. Power Sources 215116

[8] Zhao M, Fu Y, Xu N, Li G and Gao X 2014 J. Mater. Chem. A 215070

[9] Doi T, Yatomi S, Kida T, Okada S and Yamaki J 2009 Cryst. Growth Des. 910
[10] Zhu K, Zhang W, Du J et al 2015 J. Power Sources 300 139

[11] Su K, Liu F and Chen J 2013 J. Power Sources 232234

[12] Moon S, Muralidharan P and Kim D K 2012 Ceram. Int. $38 \mathrm{~S} 471$

[13] Jo M, Yoo H, Jung Y S and Cho J 2012 J. Power Sources 216162

[14] Gan Y, Chen C, Liu J, Bian P, Hao H and Yu A 2015 J. Alloys Compd. 620350

[15] Ottmann A, Jähne C, Meyer H-P and Klingeler R 2015 Mater. Res. Bull. 636

[16] Gu Y, Wang H, Zhu Y, Wang L, Qian Y and Chu Y 2015 Solid State Ion 274106

[17] Kwon N H and Fromm K M 2012 Electrochim. Acta 69 38

[18] Cui Y-T, Xu N, Kou L-Q, Wu M-T and Chen L 2014 J. Power Sources 24942

[19] Nam T, Doan L, Bakenov Z and Taniguchi I $2010 \mathrm{Adv}$. Powder Technol. 21187

[20] Kou L, Chen F, Tao F, Dong Y and Chen L 2015 Electrochim. Acta 173721

[21] Lee J, Park M, Anass B, Park J, Paik M and Doo S 2010 Electrochim. Acta 554162

[22] Hu C, Yi H, Fang H et al 2010 Electrochem. Commun. 121784

[23] Wang J, Lin W, Wu B and Zhao J 2014 Electrochim. Acta 145245

[24] He Wei, Yuan D, Qian J, Ai X, Yang H and Cao Y 2013 J. Mater. Chem. A 111397

[25] Chen Z, Xie T, Li L and Xu M 2014 Ionics 20629

[26] Hee W, Yuan D, Qian J, Ai X, Yang A and Cao Y 2013 J. Mater. Chem. A 111397

[27] Oh R-G, Hong J-E, Jung H-W and Ryu K-S 2015 J. Power Sources 2951

[28] Qiu B, Wang J, Xia Y, Liu Y, Qin L, Yao X and Liu Z 2013 J. Power Sources 240530

[29] Park S H, Shin S S and Sun Y K 2006 Mater. Chem. Phys. 95218

[30] Sun F and Xu Y 2014 J. Alloys Compd. 584538

[31] Gong C, Lv W, Qu L et al 2014 J. Power Sources 247151

[32] Hu G, Zhang M, Liang L, Peng Z, Du K and Cao Y 2016 Electrochim. Acta 190264 